\title{
How the Internet is Changing Gambling: Findings from an Australian Prevalence Survey
}

\author{
Sally M. Gainsbury • Alex Russell • Nerilee Hing • \\ Robert Wood · Dan Lubman • Alex Blaszczynski
}

Published online: 11 August 2013

(C) Springer Science+Business Media New York 2013

\begin{abstract}
Interactive gambling as a regulated activity, coupled with easy accessibility to offshore providers represents a new mode and format of gambling superimposed on traditional land-based opportunities. This paper aimed to investigate the prevalence of gambling among Australian adults and the relationship between various gambling activities and interactive modes of access. A second aim was to compare interactive and noninteractive gamblers in terms of socio-demographic characteristics, attitudes and beliefs about gambling and gambling participation. In a nationally representative telephone survey, 15,006 Australian adults completed measures assessing past 12-month gambling participation and a sub-sample completed questions about interactive gambling and beliefs.
\end{abstract}

S. M. Gainsbury $(\bowtie) \cdot$ A. Russell $\cdot$ N. Hing $\cdot$ A. Blaszczynski

Centre for Gambling Education and Research, Southern Cross University,

P.O. Box 157, Lismore, NSW 2480, Australia

e-mail: sally.gainsbury@scu.edu.au

A. Russell

e-mail: alex.russell@sydney.edu.au

N. Hing

e-mail: nerilee.hing@scu.edu.au

A. Blaszczynski

e-mail: alex.blaszczynski@sydney.edu.au

S. M. Gainsbury · A. Russell · A. Blaszczynski

School of Psychology, University of Sydney, Brennan MacCallum Building (A18),

Sydney, NSW 2006, Australia

R. Wood

Department of Sociology, University of Lethbridge, 4401 University Drive,

Lethbridge, AB T1K 3M4, Canada

e-mail: robert.wood@uleth.ca

D. Lubman

Turning Point Alcohol and Drug Centre, Eastern Health and Monash University,

Fitzroy, VIC, Australia

e-mail: dan.lubman@monash.edu 
The majority of participants $(64.3 \%)$ reported gambling at least once, with $8.1 \%$ having gambled online. Interactive gamblers gambled on a greater number of activities overall and more frequently. Interactive gamblers were more likely to be male, younger, have home Internet access, participate in more forms of gambling and have higher gambling expenditure. Almost half of the interactive gamblers preferred land-based gambling although a small proportion also noted a number of disadvantages of interactive gambling. This study shows that the nature of gambling participation is shifting with interactive gambling having a significant and growing impact on overall gambling involvement.

Keywords Internet gambling · Participation · Online gambling ·

Socio-demographic factors · Advantages · Prevalence

\section{Introduction}

Legislation over the past several decades has resulted in greater accessibility and social acceptance of gambling. One of the most significant changes to the gambling environment in the past 15 years has been the increased availability of interactive gambling (Gainsbury 2012; Wood and Williams 2011). Interactive gambling, a term largely interchangeable with Internet, remote and online gambling, refers to the range of activities (including wagering and gaming) that are offered through interactive media, including computers, mobile and smart phones, tablets, and digital television. This mode of gambling, facilitated by technological advances, is distinct from in person, terrestrial or land-based outlets, and placing wagers over the telephone. Industry reports indicate that participation in interactive gambling is increasing and expenditure via this mode represents approximately $10 \%$ of the global gambling market (Global Betting and Gaming Consultants 2011; Pricewaterhouse Coopers 2011). Internationally, an increasing number of jurisdictions are legalizing and regulating interactive gambling in recognition of the difficulties associated with enforcing prohibition and the benefits of regulation, including requiring harm minimization measures and taxation revenue (Gainsbury and Wood 2011).

Australians are highly involved gamblers; the last national prevalence survey in Australia, conducted in 1998/9, found that $82 \%$ of Australian adults had gambled in the previous 12 months, with the most popular forms being lottery $(60 \%)$, instant scratch tickets (46\%), electronic gaming machines (EGMs) (39\%) and racing (24\%; Productivity Commission 1999). Approximately $0.6 \%$ of Australians reported gambling on the Internet and $6 \%$ reported participating in sports betting. In 2001, the 2001 Interactive Gambling Act prohibited all interactive gambling, with the exception of licensed wagering (but not including in-play betting) and lottery activities. This created a context of partially legalized interactive gambling in which some online wagering is provided legally, but over 2,200 offshore interactive gambling and wagering sites provide services to Australians in contravention of federal laws (Gainsbury and Wood 2011).

In 2010, the Productivity Commission estimated that between 0.1 and $4.3 \%$ of adults gamble online each year (Productivity Commission 2010). Although the prevalence of interactive gambling appears to be relatively low compared to other forms of gambling, participation appears to be increasing rapidly, growing at $17 \%$ per annum from 2004 to 2011 (H2 Gambling Capital 2012). Australian's land-based gambling expenditure reportedly declined in 2012, however, interactive gambling options are growing in popularity 
with approximately AUD $\$ 1.1$ billion per year being gambled on regulated sites (Roy Morgan Research 2012), indicating that it may be replacing traditional in-venue gambling. Given the marked changes in the nature of gambling and its availability, it is important to investigate prevalence rates of gambling participation. As interactive gambling revenues are reportedly increasing and marketing of Internet wagering has substantially risen (Lamont et al. 2011), it is important to consider whether interactive gamblers represent a new cohort of players, whether existing gamblers are shifting how they engage in existing activities, or whether gamblers are participating in a wider variety of gambling.

A commonly cited concern in relation to regulated interactive gambling is the impact of expanding online gambling access on the existing land-based gambling industry (Gainsbury and Wood 2011). To date, international studies suggest that legalization and regulation of interactive gambling does not appear to generate large increases in Internet gambling or overall gambling participation (Humphreys and Perez 2012; Philander and Fiedler 2012; Wardle et al. 2011). Previous studies show that the majority of interactive gamblers are also land-based gamblers (Gainsbury et al. 2012; Svensson and Romild 2011; Wardle et al. 2011; Wood and Williams 2011). Analysis of the 2010 British gambling prevalence survey found several subgroups of interactive gamblers based on their involvement (Wardle et al. 2011). The majority of interactive gamblers appeared to use this mode of access as a choice of convenience, for example to purchase lottery tickets and engage in activities that they also did at land-based venues. These gamblers were characterized by high levels of gambling involvement overall. This is consistent with the most frequently reported advantages of interactive gambling being convenience and ease of access (Gainsbury et al. 2012; Wood and Williams 2010). Despite these advantages, a substantial proportion of interactive gamblers report disadvantages of this mode, including a poorer physical and social atmosphere and concerns about the fairness of games and cheating by operators (Gainsbury et al. 2012, 2013a; Wood and Williams 2010). There is also some evidence that the constant accessibility of interactive gambling and use of electronic funds poses risks for some players (Gainsbury et al. 2013b; Griffiths et al. 2009; Wood and Williams 2011). Therefore, for some gamblers' their use of interactive gambling may be based on convenience rather than a preference for this mode as compared to land-based forms.

There is some evidence to suggest that interactive gamblers represent a distinct cohort of gamblers. Surveys have found that in comparison to land-based gamblers, interactive gamblers are more likely to be male, younger, from high socio-economic backgrounds, employed full-time, have access to the Internet, and be better educated (Gainsbury et al. 2012; Griffiths et al. 2009; Wardle et al. 2011; Wood and Williams 2011). However, although some sociodemographic characteristics and behaviors are predictive of interactive gambling, this group is heterogeneous and should be considered in terms of their overall gambling involvement and a wide range of factors (Wardle et al. 2011; Gainsbury et al. 2013b). For example, some interactive gamblers consider themselves to be professional gamblers and have more positive views about the impacts of gambling (Radburn and Horsley 2011), and access to the Internet is also likely to be relevant to the use of interactive forms of gambling.

With consideration of the technological developments that are changing the nature of gambling and the increased use of interactive forms, the current study aimed to determine the 12-month prevalence of gambling participation in the Australian adult population. A secondary aim was to investigate the use of interactive forms of gambling in comparison with land-based forms and consider whether interactive gambler represent a distinct cohort of gamblers. Interactive gambling was measured as a mode of access, as previous studies that have attempted to measure interactive gambling as an independent form of gambling are likely to have misrepresented the prevalence of this activity. 


\section{Method}

A random digit dial telephone survey of a nationally representative sample of registered telephone numbers (excluding non-registered mobiles) was conducted in November and December 2011 using a computer-assisted telephone interview. The household interviewee was randomly selected by requesting the interview be conducted with the person aged 18 or older having the next birthday. Maximal effort was made to complete each interview with the randomly designated person. This included multiple call backs and phone calls on evenings and weekends.

The survey was introduced as an important national study concerning popular pastimes and leisure habits of Australians conducted through two Australian universities. This introduction was used to minimize oversampling of gamblers who are more likely to agree to be involved in gambling-specific surveys (Williams and Volberg 2009). In total 15,006 Australian adults participated in the survey (47.5\% male, aged 18-100 years of age), which represented a $26.4 \%$ response rate that is similar to Australian telephone surveys for other public health issues including smoking (Dunlop et al. 2011). All participants completed the screening questions and those who had not gambled in the past 12 months $(\mathrm{N}=5,408)$ were not asked any further questions. All interactive gamblers $(\mathrm{n}=849)$ and a randomly selected sub-sample of those who reported only land-based gambling in the last 12 months $(\mathrm{n}=1,161)$ completed the full survey $(\mathrm{N}=2,010)$. The study obtained ethical approval from the relevant institutional review boards of the two universities directly involved in data collection.

\section{Measures}

The telephone survey questionnaire included 10 main sections, although only the measures relevant to the current paper are described here. Surveys usually took up to $25 \mathrm{~min}$, primarily depending on the extent of gambling involvement of the participant.

\section{Demographics}

Demographic variables were measured to match the most recent Census data and included gender, year of birth, household size and current living arrangement, locality and postcode, marital status, educational level, employment, county of birth, language spoken at home, and whether participants were of Australian Aboriginal or Torres Strait Islander descent (ATSI).

\section{Gambling Behavior}

Participants were asked how often they had participated (times per week, month or year) in 10 different gambling activities in the past 12 months. Those who had participated at least once were asked whether they had used an interactive mode for each activity. Gambling activities asked about included lottery tickets, instant scratch tickets, horse or dog race betting, EGMs, sports betting, keno, casino table games, poker, bingo and betting on skill games. For each gambling activity used, participants were asked whether they had gambled using interactive modes and their typical monthly expenditure. 


\section{Patterns and Preferences of Interactive Gambling}

Six questions concerned with patterns and preferences of interactive gamblers including: year when they first started using the Internet for gambling, their preferred devices, their interactive gambling preferences, impacts on spending by using credit card/electronic money transfer, and impacts of interactive gambling on sleeping and eating patterns.

\section{Gambling Attitudes}

One item from the Gambling Attitudes Scale (Gainsbury et al. 2012) about respondents' views about the benefit or harm that gambling has for society. Gamblers were asked whether they thought that the benefits of gambling outweighed the harms with five response options available.

\section{Problem Gambling Severity Index (PGSI)}

Nine questions that comprise the Problem Gambling Severity Index (PGSI; Ferris and Wynne 2001) were administered. Questions assessed the extent of gambling-related harm experienced over the previous 12 months and total scores indicate the risk level of gambling problems for each participant. In this survey, the PGSI was administered to a subset of participants to avoid participant fatigue amongst low-frequency gamblers and to reduce false positive rates (Williams and Volberg 2012). The PGSI was not administered to those who only reported playing either bingo or lottery less than weekly.

\section{Alcohol, Tobacco, Substance Use and Mental Health}

Seven questions created for this survey requested information about the frequency of cigarette smoking, drinking alcohol and illegal drug use and substance use while gambling. The six question Kessler Psychological Distress Scale (K6; Kessler et al. 2002) asked the frequency of symptoms of psychological distress with the total score indicating levels of psychological distress.

Analysis

Consistent with previous studies (Gainsbury et al. 2012; Griffiths et al. 2009; Olason et al. 2011; Productivity Commission 1999; Wardle et al. 2011; Wood and Williams 2011), an interactive gambler was defined as anyone who used an interactive mode of gambling at least once in the past 12 months. A non-gambler was defined as anyone who had not engaged in any of the surveyed forms of gambling at least once in the past 12 months. Non-interactive gamblers were defined as a participant who had gambled at least once in the past 12 months, but did not report using any interactive forms.

Two weights were applied to the data: a design weight to correct for sampling one adult per household and a post-stratification weight to correct for age $\mathrm{x}$ gender cell size against the 2011 Australian census. All interactive gamblers were retained, whereas an approximately equal number of non-interactive gamblers were surveyed after the screening questions. As $100 \%$ of interactive gamblers and $13.3 \%$ of non-interactive gamblers were selected for the majority of questions in the survey, these proportions were accounted for in population prevalence calculations. Weights were also normed so that the weighted $\mathrm{N}$ for each analysis was equal to the unweighted $\mathrm{N}$. 
Pearson Chi square analyses or $t$ tests, using a significance criterion of $p<0.05$, were carried out to test for statistically significant differences between proportions or between mean values of variables of interest. Follow up tests for the Chi square analyses were conducted using a Bonferroni-adjusted $z$ test. A multivariate analysis was conducted in order to determine which factors uniquely predict interactive gambling participation. Some independent variables were excluded from this analysis due to issues with the assumptions for the analysis.

\section{Results}

\section{Participation}

After the data weighting, the past-year adult prevalence rate of gambling in Australia in 2010/2011 was calculated as $64.3 \%$. Table 1 shows the past year prevalence of different gambling activities amongst the Australian adult population. As can be seen, purchasing lottery, lotto, or pools tickets $(43.2 \%)$ or instant scratch tickets $(31.5 \%)$ were the most common forms of gambling, while playing bingo (2.9\%) or betting on skill games $(1.6 \%)$ were the least common amongst the Australian adult population in 2010/2011.

The past-year adult prevalence rate of interactive gambling in Australia in 2011 was $8.1 \%$. As shown in Table 2, two of the top three forms of gambling for both interactive and non-interactive gamblers were lottery-type games, and horse or dog race betting. A significantly higher proportion of interactive gamblers engaged in horse and dog racing betting, EGMs, sports betting, keno, casino table games, poker, bingo and betting on skill games as compared to non-interactive gamblers. However, no significant differences were observed in the proportion of interactive and non-interactive gamblers who bought lottery or instant scratch tickets.

Interactive gamblers engaged in significantly more of the gambling activities surveyed $(\mathrm{M}=3.6 ; \mathrm{SD}=2.0)$ compared to non-interactive gamblers $(\mathrm{M}=2.3 ; \mathrm{SD}=1.4)$, $t(1,882.48)=17.16, p<0.001, d=0.76$. Non-parametric tests were used to compare interactive and non-interactive gamblers in terms of frequency of gambling on each activity, due to a large amount of variance in the data. Interactive gamblers engaged in sports betting $(U(721)=26,976.5, \quad Z=7.06, \quad p<0.001), \quad$ race $\quad$ wagering $(U(950)=59,191, Z=9.17, p<0.001)$, betting on games of skill $(U(66)=310.5$, $Z=2.26, \quad p=0.024), \quad$ EGMs $\quad(U(685)=41,553.5, \quad Z=4.60, \quad p<0.001), \quad$ keno

Table 1 Past year prevalence of participation in different forms of gambling amongst the Australian adult population in 2010/2011
Weighted by product of design and post-stratification weights. Multiple responses possible

\begin{tabular}{ll}
\hline Form of gambling & Weighted \% of population \\
\hline Lottery, lotto or pools tickets & 43.2 \\
Instant scratch tickets & 31.5 \\
Horse or dog race betting & 22.4 \\
EGMs & 19.4 \\
Sports betting & 13.3 \\
Keno & 8.9 \\
Casino table games & 8.7 \\
Poker & 5.9 \\
Bingo & 2.9 \\
Betting on skill games & 1.6 \\
\hline
\end{tabular}


Table 2 Past year prevalence of participation in different forms of gambling for interactive and noninteractive gamblers $(\mathrm{N}=2,010)$

\begin{tabular}{|c|c|c|c|}
\hline Form of gambling & $\begin{array}{l}\text { Interactive } \\
\text { gamblers } \mathrm{N}(\%)\end{array}$ & $\begin{array}{l}\text { Non-interactive } \\
\text { gamblers N }(\%)\end{array}$ & Test statistic \\
\hline Lottery, lotto or pools tickets & $712(67.6)$ & $643(67.2)$ & $\begin{array}{l}\chi^{2}(1, N=2,011)=0.03 \\
\quad p=0.862\end{array}$ \\
\hline Instant scratch tickets & $548(52.0)$ & $465(48.6)$ & $\begin{array}{l}\chi^{2}(1, N=2,010)=2.25 \\
\quad p=0.133\end{array}$ \\
\hline Horse or dog race betting & $677(64.2)^{*}$ & $293(30.7)$ & $\begin{array}{c}\chi^{2}(1, N=2,010)=226.43 \\
p<0.001, \Phi=0.34\end{array}$ \\
\hline EGMs & $453(43.0)^{*}$ & $272(28.4)$ & $\begin{array}{c}\chi^{2}(1, N=2,010)=46.33 \\
p<0.001, \Phi=0.15\end{array}$ \\
\hline Sports betting & $569(54.0)^{*}$ & $152(15.9)$ & $\begin{array}{c}\chi^{2}(1, N=2,010)=316.10 \\
p<0.001, \Phi=0.40\end{array}$ \\
\hline Keno & $195(18.5)^{*}$ & $127(13.3)$ & $\begin{array}{c}\chi^{2}(1, N=2,011)=10.20 \\
p=0.001, \Phi=0.07\end{array}$ \\
\hline Casino table games & $301(28.6)^{*}$ & $109(11.4)$ & $\begin{array}{c}\chi^{2}(1, N=2,010)=91.30 \\
p<0.001, \Phi=0.21\end{array}$ \\
\hline Poker & $210(19.9)^{*}$ & $74(7.7)$ & $\begin{array}{c}\chi^{2}(1, N=2,010)=61.61 \\
p<0.001, \Phi=0.18\end{array}$ \\
\hline Bingo & $76(7.2)^{*}$ & $40(4.2)$ & $\begin{array}{c}\chi^{2}(1, N=2,011)=8.48 \\
p=0.004, \Phi=0.07\end{array}$ \\
\hline Betting on skill games & $43(4.1)^{*}$ & $21(2.2)$ & $\begin{array}{c}\chi^{2}(1, N=2,010)=5.77 \\
p=0.016, \Phi=0.05\end{array}$ \\
\hline
\end{tabular}

Weighted by product of design and post-stratification weights

* Significantly higher proportions per form of gambling

$(U(317)=8,326, Z=4.66, p<0.001)$ and casino table games $(U(410)=11,205$, $Z=4.97, p<0.001)$ significantly more frequently than non-interactive gamblers.

\section{Attitudes and Beliefs About Gambling}

Of non-interactive gamblers, $47.0 \%$ believed that the harm of gambling far outweighs the benefits compared to $33.3 \%$ of interactive gamblers, while $8.0 \%$ of interactive gamblers believed that the benefits somewhat outweigh the harm, compared to $3.1 \%$ of noninteractive gamblers. Both of these differences, shown in Table 3, were statistically significant. However, more than two-thirds of each group believes that the harms of gambling outweigh the benefits, $\chi^{2}(4, N=1,924)=51.18, p<0.001, \Phi=0.16$.

\section{Descriptive Differences Between Interactive and Non-Interactive Gamblers}

As shown in Table 4, a significantly higher proportion of interactive gamblers were male $(62.4 \%)$ compared to non-interactive gamblers $(48.0 \%)$. Interactive gamblers were significantly younger $(M=37.3, S D=14.1)$ than non-interactive gamblers $(M=45.1$, $S D=17.4), t(1,834.1)=11.02, p<0.001, d=0.50$. Interactive gamblers were more likely to be living with a partner/de facto or never married, while non-interactive gamblers were more likely to be married or widowed. In terms of education, a significantly higher proportion of interactive gamblers had an undergraduate degree or a year 12 certificate, while non-interactive gamblers were significantly more likely to have learned a trade or 
Table 3 Perceived benefit and harm of gambling to society for interactive and non-interactive gamblers $(N=1,924)$

\begin{tabular}{lccccc}
\hline Perceived benefit and harm of gambling & \multicolumn{2}{c}{ Interactive gamblers } & & Non-interactive gamblers \\
\cline { 5 - 6 } \cline { 5 - 6 } & $\mathrm{N}$ & $\%$ & & $\mathrm{~N}$ & $\%$ \\
\hline The harm far outweighs the benefits & 341 & 33.3 & & 422 & $46.9 *$ \\
The harm somewhat outweighs the benefits & 357 & 34.8 & & 277 & 30.8 \\
The benefits are about equal to the harm & 207 & 20.2 & & 152 & 16.9 \\
The benefits somewhat outweigh the harm & 82 & $8.0 *$ & & 28 & 3.1 \\
The benefits far outweigh the harm & 38 & 3.7 & & 20 & 2.2 \\
$\chi^{2}(4, N=1,924)=51.18, p<0.001, \Phi=0.16$ & & & &
\end{tabular}

Weighted by product of design and post-stratification weights. The weights were normed so that total $\mathrm{N}=1,980$. The total $\mathrm{N}$ is different due to rounding and refused responses

hold a technical certificate or diploma. Interactive gamblers were significantly more likely to be employed full-time, or to be a full-time student, while non-interactive gamblers were significantly more likely to be employed part-time or retired. A significantly higher proportion of interactive gamblers lived in a group household or in a one parent family with children, while non-interactive gamblers were more likely to live in single person households, or as a couple with children.

A significantly higher proportion of interactive gamblers resided in Victoria, whereas a significantly higher proportion of non-interactive gamblers resided in Western Australia, with no other significant state or territory differences observed. In terms of Internet access, a significantly higher proportion of interactive gamblers had broadband Internet access both at home and their place of work, while a higher proportion of non-interactive gamblers did not have Internet access at home and at work. Finally, $2.9 \%$ of interactive gamblers considered themselves to be professional gamblers, compared to $0.4 \%$ of noninteractive gamblers. The difference is statistically significant. No significant differences were observed in terms of country of birth, Aboriginal or Torres Strait Island origin status or whether English is predominantly spoken at home.

\section{Interactive Gambling}

All 849 interactive gamblers were asked about their use of the Internet for gambling purposes. The following analyses were weighted for household number and age $\mathrm{x}$ gender and were normed so that the total $\mathrm{N}$ was 849 , as this was the actual unweighted number of interactive gamblers in the sample. Just over half (54.9\%) of interactive gamblers first accessed the Internet for gambling purposes in or later than 2009. A similar proportion $(52.4 \%)$ preferred Internet gambling to telephone or land-based gambling although $42.5 \%$ reported a preference for land-based forms. The majority $(87.1 \%)$ of interactive gamblers preferred to access Internet gambling via computer or laptop, with a further $9.4 \%$ preferring to use their mobile or smart phone and $2.5 \%$ preferring to use a portable device, such as a tablet. Most $(71.2 \%)$ believed that using a credit card or electronic money transfer has no impact on their spending, while $17.2 \%$ stated that it had increased their spending. A minority $(9.6 \%)$ reported sleep disruption or a disruption to their eating patterns $(3.5 \%)$ due to their interactive gambling. 
Table 4 Demographic comparisons between interactive and non-interactive gamblers (weighted $\mathrm{N}=2,010)$

\begin{tabular}{|c|c|c|c|c|}
\hline \multirow[t]{2}{*}{ Demographic factor } & \multicolumn{2}{|c|}{ Interactive gamblers } & \multicolumn{2}{|c|}{ Non-interactive gamblers } \\
\hline & $\mathrm{N}$ & $\%$ & $\mathrm{~N}$ & $\%$ \\
\hline \multicolumn{5}{|l|}{ Gender } \\
\hline Male & 658 & $62.4^{*}$ & 459 & 48.0 \\
\hline Female & 396 & 37.6 & 498 & $52.0 *$ \\
\hline \multicolumn{5}{|l|}{$\chi^{2}(1, N=2,011)=42.51, p<0.001, \Phi=0.15$} \\
\hline \multicolumn{5}{|l|}{ Age group } \\
\hline $18-19$ years & 52 & 4.9 & 58 & 6.1 \\
\hline 20-24 years & 184 & $17.5^{*}$ & 101 & 10.6 \\
\hline $25-29$ years & 169 & $16.0^{*}$ & 74 & 7.8 \\
\hline $30-34$ years & 112 & $10.6^{*}$ & 59 & 6.2 \\
\hline $35-39$ years & 127 & $12.1 *$ & 87 & 9.1 \\
\hline $40-44$ years & 95 & 9.0 & 95 & 9.9 \\
\hline $45-49$ years & 90 & 8.5 & 94 & 9.8 \\
\hline $50-54$ years & 78 & 7.4 & 92 & 9.6 \\
\hline $55-59$ years & 64 & 6.1 & 84 & $8.8^{*}$ \\
\hline $60-64$ years & 39 & 3.7 & 64 & $6.7 *$ \\
\hline 65 or more years old & 44 & 4.2 & 147 & $15.4^{*}$ \\
\hline \multicolumn{5}{|l|}{$\chi^{2}(10, N=2,009)=146.58, p<0.001, \Phi=0.27$} \\
\hline \multicolumn{5}{|l|}{ Marital status } \\
\hline Married & 479 & 45.4 & 562 & $59.0^{*}$ \\
\hline Living with partner/de facto & 157 & $14.9 *$ & 80 & 8.4 \\
\hline Widowed & 10 & 0.9 & 36 & $3.8^{*}$ \\
\hline Divorced or separated & 58 & 5.5 & 55 & 5.8 \\
\hline Never married & 351 & $33.3^{*}$ & 219 & 23.0 \\
\hline \multicolumn{5}{|l|}{$\chi^{2}(4, N=2,007)=71.88, p<0.001, \Phi=0.19$} \\
\hline \multicolumn{5}{|l|}{ Highest level of education } \\
\hline Postgraduate degree & 98 & 9.3 & 108 & 11.3 \\
\hline University/college & 295 & $28.0^{*}$ & 215 & 22.5 \\
\hline Apprenticeship, technical certificate, diploma & 239 & 22.7 & 247 & $25.8 *$ \\
\hline Year 12 or equivalent & 298 & $28.3 *$ & 190 & 19.9 \\
\hline Year 10 or equivalent & 116 & 11.0 & 173 & $18.1 *$ \\
\hline Less than year 10 & 8 & 0.7 & 23 & $2.4^{*}$ \\
\hline \multicolumn{5}{|l|}{$\chi^{2}(5, N=2,010)=50.91, p<0.001, \Phi=0.16$} \\
\hline \multicolumn{5}{|l|}{ Work status } \\
\hline Full-time employment & 538 & $51.0^{*}$ & 336 & 35.1 \\
\hline Part-time or casual employment & 187 & 17.7 & 210 & $22.0 *$ \\
\hline Self employed & 86 & 8.2 & 73 & 7.6 \\
\hline Unemployed and looking for work & 29 & 2.7 & 36 & 3.8 \\
\hline Full-time student & 86 & $8.2 *$ & 56 & 5.9 \\
\hline Full-time home duties & 40 & 3.8 & 49 & 5.1 \\
\hline Retired & 56 & 5.3 & 155 & $16.2 *$ \\
\hline Sick or disability pension & 19 & 1.8 & 24 & 2.5 \\
\hline Other & 14 & 1.3 & 17 & 1.8 \\
\hline
\end{tabular}


Table 4 continued

\begin{tabular}{|c|c|c|c|c|}
\hline \multirow[t]{2}{*}{ Demographic factor } & \multicolumn{2}{|c|}{ Interactive gamblers } & \multicolumn{2}{|c|}{ Non-interactive gamblers } \\
\hline & $\mathrm{N}$ & $\%$ & $\mathrm{~N}$ & $\%$ \\
\hline
\end{tabular}

$\chi^{2}(8, N=2,011)=99.77, p<0.001, \Phi=0.22$

Current living arrangement

Single person

One parent family with children

Couple with children

Couple with no children

Group household

Other

$\chi^{2}(5, N=2,006)=63.85, p<0.001, \Phi=0.18$

Country of birth

Australia

Other-total

$\chi^{2}(1, N=2,010)=1.12, p=0.29$

State or territory

New South Wales

Victoria

Queensland

South Australia

Western Australia

Tasmania

Northern Territory

Australian Capital Territory

$\chi^{2}(7, N=2,011)=33.93, p<0.001, \Phi=0.13$

Aboriginal/Torres Strait Island origin

No

Yes, Aboriginal only

$\chi^{2}(1, N=2,007)=0.22, p=0.64$

Internet access at home

No internet connection

Broadband (ADSL, cable, wireless, satellite)

Dial-up (analogue modem, ISDN)

$\chi^{2}(2, N=1,999)=60.27, p<0.001, \Phi=0.17$

Internet access at work

No internet connection

Broadband (ADSL, cable, wireless, satellite)

Dial-up (Analogue modem, ISDN)

$\chi^{2}(2, N=1,701)=22.94, p<0.001, \Phi=0.12$

English spoken at home

No

Yes

65

566

$\chi^{2}(1, N=1,230)=1.10, p=0.30$

$\begin{array}{rcrc}79 & 7.5 & 102 & 10.7 * \\ 81 & 7.7 * & 47 & 4.9 \\ 548 & 52.1 & 552 & 57.8^{*} \\ 170 & 16.2 & 184 & 19.3 \\ 149 & 14.2 * & 45 & 4.7 \\ 24 & 2.3 & 25 & 2.6\end{array}$

$\begin{array}{llll}864 & 82.0 & 766 & 80.1\end{array}$

$\begin{array}{llll}190 & 18.0 & 190 & 19.9\end{array}$

$\begin{array}{rcrc}346 & 32.8 & 312 & 32.6 \\ 335 & 31.8^{*} & 215 & 22.5 \\ 180 & 17.1 & 186 & 19.4 \\ 72 & 6.8 & 81 & 8.5 \\ 83 & 7.9 & 116 & 12.1^{*} \\ 20 & 1.9 & 23 & 2.4 \\ 12 & 1.1 & 9 & 0.9 \\ 6 & 0.6 & 15 & 1.6\end{array}$

$\begin{array}{rcrr}17 & 1.6 & 86 & 9.1^{*} \\ 1,020 & 97.1^{*} & 840 & 88.6 \\ 14 & 1.3 & 22 & 2.3\end{array}$

$\begin{array}{rcrc}182 & 19.9 & 235 & 29.9^{*} \\ 721 & 78.8^{*} & 541 & 68.8 \\ 12 & 1.3 & 10 & 1.3\end{array}$


Table 4 continued

\begin{tabular}{|c|c|c|c|c|}
\hline \multirow[t]{2}{*}{ Demographic factor } & \multicolumn{2}{|c|}{ Interactive gamblers } & \multicolumn{2}{|c|}{ Non-interactive gamblers } \\
\hline & $\mathrm{N}$ & $\%$ & $\mathrm{~N}$ & $\%$ \\
\hline \multicolumn{5}{|c|}{ Consider myself to be a professional gambler } \\
\hline No & 1,024 & 97.1 & 952 & $99.6^{*}$ \\
\hline Yes & 30 & $2.9^{*}$ & 4 & 0.4 \\
\hline \multicolumn{5}{|c|}{$\chi^{2}(1, N=2,010)=17.77, p<0.001, \Phi=0.09$} \\
\hline
\end{tabular}

Weighted by product of design and post-stratification weights. The weights were re-normed so that total $\mathrm{N}=2,010$. In some cases, the total $\mathrm{N}$ is slightly different due to rounding

* The proportion of respondents in that category from that group (either interactive or non-interactive gamblers) is significantly higher than the proportion of respondents from the other group

\section{Characteristics Statistically Differentiating Interactive Gamblers from Non-Interactive Gamblers}

The previous bivariate analyses do not control for extraneous factors, so multivariate analyses were conducted in order to determine which factors uniquely differentiate interactive and non-interactive gamblers. Logistic regression was used to model the relationships of measured and calculated variables with interactive or non-interactive gambling as the response variable. Demographic variables and other variables of known importance for the analysis of interactive gambling were entered into the equation simultaneously. Due to low numbers in certain categories, some variables were recoded and are shown along with the reference categories in Table 5.

Overall, the model correctly categorized $72.5 \%$ of interactive and non-interactive gamblers and was significant, $\chi^{2}(40, N=745)=237.53, p<0.001$. Furthermore, the model predicts both categories with approximately the same success, correctly predicting $73.2 \%$ of interactive gamblers and $71.7 \%$ of non-interactive gamblers. The dependent variable was coded as 0 "non-interactive gambler" and 1 "interactive gambler", such that odds ratios (ORs) higher than 1 indicate that those with higher levels of that independent variable are more likely to be interactive gamblers.

As can be seen from Table 5, the variables that significantly predicted interactive gambling were: being male $(\mathrm{OR}=0.45, p<0.001)$, being younger $(\mathrm{OR}=0.973$, $p=0.002$ ), having home Internet access (OR $=0.20, p=0.001)$, participating in more forms of gambling $(\mathrm{OR}=0.70, p<0.001)$ and losing more money per year on gambling $(\mathrm{OR}=0.64, p<0.035)$.

\section{Discussion}

This is the first national prevalence study of gambling conducted in Australia since 1999 (Productivity Commission 1999) and the first to specifically investigate the use of interactive gambling. Results showed that fewer Australian adults gambled in 2011 than in 1998/9, representing a $21 \%$ decrease in annual gambling participation. The preferred forms of gambling, lottery, instant scratch tickets, race betting and EGMs, are consistent with gambling patterns reported in 1999, although the current results indicate that annual participation in race betting is now greater than EGM gambling. Participation in all gambling activities decreased with the exception of sports betting which more than 
Table 5 Logistic regression of characteristics differentiating Australian interactive gamblers from noninteractive gamblers

\begin{tabular}{|c|c|c|c|c|c|c|c|}
\hline Predictor & $\mathrm{b}$ & $\begin{array}{l}\text { Std } \\
\text { error b }\end{array}$ & Wald & $p$ & $\begin{array}{l}\text { Odds } \\
\text { ratio }\end{array}$ & $\begin{array}{l}95 \% \text { CI } \\
\text { lower }\end{array}$ & $\begin{array}{l}95 \% \mathrm{Cl} \\
\text { upper }\end{array}$ \\
\hline $\begin{array}{l}\text { Problem gambling severity index } \\
\text { score }\end{array}$ & -0.08 & 0.07 & 1.35 & 0.246 & 0.93 & 0.81 & 1.06 \\
\hline Gender (ref female) & -0.80 & 0.20 & 16.42 & $<0.001$ & 0.45 & 0.31 & 0.66 \\
\hline Age (in years) & $\mathbf{0 . 0 3}$ & 0.01 & 9.31 & 0.002 & 1.03 & 1.01 & 1.05 \\
\hline \multicolumn{8}{|l|}{ Marital status (ref married) } \\
\hline Living with partner/de facto & 0.01 & 0.32 & 0.00 & 0.977 & 1.01 & 0.54 & 1.88 \\
\hline Widowed & 0.38 & 0.67 & 0.31 & 0.577 & 1.46 & 0.39 & 5.46 \\
\hline Divorced or separated & 0.48 & 0.55 & 0.78 & 0.378 & 1.62 & 0.56 & 4.71 \\
\hline Never married & 0.49 & 0.48 & 1.02 & 0.314 & 1.63 & 0.63 & 4.18 \\
\hline \multicolumn{8}{|l|}{ Living arrangement (ref single person) } \\
\hline One parent family with children & -0.62 & 0.48 & 1.67 & 0.196 & 0.54 & 0.21 & 1.37 \\
\hline Couple with children & 0.61 & 0.52 & 1.37 & 0.242 & 1.84 & 0.66 & 5.07 \\
\hline Couple with no children & -0.02 & 0.54 & 0.00 & 0.975 & 0.98 & 0.34 & 2.84 \\
\hline Group household & -0.52 & 0.55 & 0.89 & 0.345 & 0.60 & 0.20 & 1.74 \\
\hline Other & -0.14 & 0.91 & 0.02 & 0.881 & 0.87 & 0.15 & 5.22 \\
\hline \multicolumn{8}{|c|}{ Education achievement (ref postgraduate) } \\
\hline Undergraduate/college & -0.31 & 0.32 & 0.97 & 0.325 & 0.73 & 0.39 & 1.36 \\
\hline Trade, tech certificate, diploma & 0.30 & 0.32 & 0.87 & 0.352 & 1.34 & 0.72 & 2.51 \\
\hline Year 12 or equivalent & -0.25 & 0.33 & 0.56 & 0.454 & 0.78 & 0.41 & 1.50 \\
\hline Year 10 or equivalent & 0.32 & 0.35 & 0.83 & 0.362 & 1.37 & 0.69 & 2.72 \\
\hline Less than year 10 & 0.53 & 0.81 & 0.43 & 0.510 & 1.71 & 0.35 & 8.34 \\
\hline \multicolumn{8}{|l|}{ Work status (ref full time) } \\
\hline Part time & 0.12 & 0.24 & 0.23 & 0.632 & 1.12 & 0.70 & 1.81 \\
\hline Self employed & -0.16 & 0.31 & 0.27 & 0.604 & 0.85 & 0.47 & 1.56 \\
\hline Retired & 0.60 & 0.40 & 2.25 & 0.134 & 1.83 & 0.83 & 4.01 \\
\hline Other & 0.20 & 0.40 & 0.24 & 0.625 & 1.22 & 0.56 & 2.66 \\
\hline Country of birth (ref not Australia) & 0.05 & 0.23 & 0.05 & 0.830 & 1.05 & 0.67 & 1.65 \\
\hline Language at home (ref not English) & -0.27 & 0.31 & 0.77 & 0.381 & 0.77 & 0.42 & 1.39 \\
\hline Indigenous status (ref non-ATSI) & 0.46 & 0.71 & 0.42 & 0.515 & 1.59 & 0.40 & 6.35 \\
\hline Tobacco use (ref none) & -0.02 & 0.23 & 0.01 & 0.938 & 0.98 & 0.63 & 1.53 \\
\hline Alcohol use (ref none) & -0.24 & 0.31 & 0.61 & 0.436 & 0.79 & 0.43 & 1.43 \\
\hline Illicit drug use (ref none) & 0.02 & 0.40 & 0.00 & 0.952 & 1.03 & 0.47 & 2.24 \\
\hline Home internet access (ref no) & -1.61 & 0.48 & 11.39 & 0.001 & 0.20 & 0.08 & 0.51 \\
\hline Work internet access (ref no) & 0.20 & 0.27 & 0.58 & 0.448 & 1.22 & 0.73 & 2.06 \\
\hline Psychological distress (Kessler 6) & -0.01 & 0.03 & 0.03 & 0.866 & 1.00 & 0.94 & 1.05 \\
\hline $\begin{array}{l}\text { Number of gambling types played } \\
\text { in last } 12 \text { months }\end{array}$ & -0.36 & 0.06 & 32.53 & $<0.001$ & 0.70 & 0.61 & 0.79 \\
\hline Gambling expenditure (\$000’s) & -0.45 & 0.22 & 4.42 & 0.035 & 0.64 & 0.42 & 0.97 \\
\hline \multicolumn{8}{|l|}{ State (reference NSW) } \\
\hline ACT & 0.59 & 0.98 & 0.36 & 0.551 & 1.80 & 0.26 & 12.26 \\
\hline Victoria & -0.43 & 0.23 & 3.34 & 0.068 & 0.65 & 0.41 & 1.03 \\
\hline Queensland & 0.08 & 0.25 & 0.11 & 0.739 & 1.09 & 0.66 & 1.79 \\
\hline
\end{tabular}


Table 5 continued

\begin{tabular}{lcllllll}
\hline Predictor & $\mathrm{b}$ & $\begin{array}{l}\text { Std } \\
\text { error b }\end{array}$ & Wald & $p$ & $\begin{array}{l}\text { Odds } \\
\text { ratio }\end{array}$ & $\begin{array}{l}95 \% \mathrm{CI} \\
\text { lower }\end{array}$ & $\begin{array}{l}\text { 95\% CI } \\
\text { upper }\end{array}$ \\
\hline South Australia & 0.42 & 0.37 & 1.26 & 0.262 & 1.52 & 0.73 & 3.16 \\
Western Australia & 0.40 & 0.33 & 1.43 & 0.231 & 1.49 & 0.78 & 2.84 \\
Tasmania & 1.29 & 0.72 & 3.22 & 0.073 & 3.63 & 0.89 & 14.80 \\
Northern Territory & 0.11 & 1.06 & 0.01 & 0.916 & 1.12 & 0.14 & 8.85 \\
Perceived harms of gambling & -0.07 & 0.09 & 0.72 & 0.395 & 0.93 & 0.79 & 1.10 \\
\hline
\end{tabular}

Significant $p$ values are shown in bold

doubled in popularity. The smallest decreases were observed for race betting and casino table games. Changes in betting on poker and other skill games are not readily apparent due to the differences in measures used between the studies.

Notably, the prevalence of interactive gambling was substantially higher than previous estimates and confirms reports of increased participation through regulated and offshore sites. No difference was observed in the likelihood of interactive and non-interactive gamblers purchasing lottery tickets, which are legally available for purchase via interactive modes in Australia. This suggests that the availability of this gambling activity online has not substantially shifted participation in this mode of gambling, which is consistent with international results (Humphreys and Perez 2012). All other gambling activities were more likely to be used by interactive as compared to non-interactive gamblers. Interactive gamblers also participated in a significantly greater total number of gambling activities and gambled more frequently on multiple forms. This confirms previous findings that interactive gamblers are overall more engaged or involved gamblers than non-interactive gamblers (Gainsbury et al. 2012; Griffiths et al. 2009; Wardle et al. 2011; Wood and Williams 2011). The greater gambling versatility may suggest that the convenience and ease of access through the Internet facilitates increased involvement in multiple forms of gambling, or alternatively, that gamblers who use interactive modes are more likely to be more highly involved in gambling activities already.

In addition to being more involved in gambling, interactive gamblers were more likely to perceive some positive impacts of gambling than non-interactive gamblers. However, the majority of all gamblers believed that the harms of gambling outweigh the benefits for society. These findings highlight the concerns that gamblers have about gambling, although also indicate that these concerns are not sufficient to stop gamblers from using these activities. Interactive gamblers were also more likely to consider themselves professional gamblers, indicating that the lower costs and higher returns associated with this mode of gambling and the ability to quickly and conveniently access multiple gambling operators and large betting markets and use computer-assisted programs enables a small proportion of players to reportedly make substantial profits from this activity. Unsurprisingly, interactive gamblers were more likely to have broadband Internet access at home and their place of work. However, the majority of non-interactive gamblers also had Internet access, indicating that access to interactive gambling is not a sufficient motivator to engage in this activity.

Consistent with previous studies, interactive gamblers were more likely to be younger, male, have Internet access at home, gamble on more activities and spend higher amounts gambling (Gainsbury et al. 2012; Griffiths et al. 2009; Wardle et al. 2011; Wood and Williams 2011). These findings suggest that interactive gamblers do represent a somewhat 
different cohort of gamblers to land-based players. As the majority started gambling online within the last five years, the impacts of this shift in participation are yet to be fully understood. However of note, two-fifths of interactive gamblers report a preference for non-interactive forms, indicating that despite the advantages of this mode of access, landbased gambling venues still serve an important function for players (Gainsbury et al. 2012; Wardle et al. 2011). A minority of interactive gamblers reported some negative consequences of this mode, including increased expenditure and disrupted eating and sleeping, highlighting some of the risks associated with the constant availability and convenience (Gainsbury et al. 2013b; Wood and Williams 2011).

It is important to be mindful of the limitations of the data when interpreting these findings. Given the low proportion of interactive gambling in the population, a large number of people had to be included to ensure a sufficient sample of interactive gamblers. By oversampling a particular population, this may have biased the total sample included, although weighting was used to make the sample as representative as possible. Only participants with landline telephones were sampled for the survey, meaning that the gambling behaviour and preferences of those who do not have a landline phone were not included. This may have resulted in an underestimate of interactive gambling rates as those who only have mobile phones may be more likely to gamble online and future studies should address this limitation.

Nonetheless, these results are highly significant as they present the first nationally representative prevalence figures since 1999. This study shows that gambling participation is declining, but interactive gambling is increasing. Interactive gamblers appear to represent a unique cohort of players demographically as well as in terms of their gambling. Internet gambling appears to be enabling highly involved gamblers to engage in a variety of gambling activities both online and offline. As interactive modes of gambling are still evolving and as participation increases it is likely that further shifts in the use of gambling will be seen.

Acknowledgments The authors would like to express their thanks and acknowledge the support of Gambling Research Australia, who provided funding for the research described in this manuscript.

Conflict of interest The authors have no conflicts of interest to declare in relation to this manuscript.

\section{References}

Dunlop, S. M., Perez, D., \& Cotter, R. (2011). Australian smokers' and recent quitters' responses to the increasing price of cigarettes in the context of a tobacco tax increase. Addiction, 106, 1687-1695.

Ferris, J., \& Wynne, H. (2001). The Canadian problem gambling index: Final report. Ottawa: Canadian Centre on Substance Abuse.

Gainsbury, S. (2012). Internet gambling: Current research findings and implications. New York: Springer.

Gainsbury, S., Parke, J., \& Suhonen, N. (2013a). Attitudes towards Internet gambling: Perceptions of responsible gambling, consumer protection, and regulation of gambling sites. Computers in Human Behavior, 29, 235-245. doi:10.1016/j.chb.2012.08.010.

Gainsbury, S., Russell, A., Hing, N., Wood, R., \& Blaszczynski, A. (2013b). The impact of Internet gambling on gambling problems: A comparison of moderate-risk and problem Internet and nonInternet gamblers. Psychology of Addictive Behaviors. Advance online publication Feb 25, 2013. doi:10.1037/a0031475.

Gainsbury, S., \& Wood, R. (2011). Internet gambling policy in critical comparative perspective: The effectiveness of existing regulatory frameworks. International Gambling Studies, 11, 309-323. 
Gainsbury, S., Wood, R., Russell, A., Hing, N., \& Blaszczynski, A. (2012). A digital revolution: Comparison of demographic profiles, attitudes and gambling behaviour of Internet and non-Internet gamblers. Computers in Human Behavior, 28, 1388-1398.

Global Betting and Gaming Consultants. (2011). Global gaming report. Castletown, Isle of Man (6th ed.). British Isles: Author.

Griffiths, M. D., Wardle, H., Orford, J., Sproston, K., \& Erens, B. (2009). Sociodemographic correlates of internet gambling: Findings from the 2007 British gambling prevalence survey. CyberPsychology and Behavior, 12, 199-202.

H2 Gambling Capital. (2012). eGaming data set. London: H2 Gambling Capital.

Humphreys, B. R., \& Perez, L. (2012). Participation in internet gambling markets: An international comparison of online gamblers' profiles. Journal of Internet Commerce, 11, 24-40.

Kessler, R. C., Andrews, G., Colpe, L., Hiripi, E., Mroczwk, D. K., Normand, S. L. T., et al. (2002). Short screening scales to monitor population prevalence and trends in non-specific psychological distress. Psychological Medicine, 32, 959-976.

Lamont, M., Hing, N., \& Gainsbury, S. (2011). Gambling on sport sponsorship: A conceptual framework for research and regulatory review. Sport Management Review, 14, 246-257.

Olason, D. T., Kristjansdottir, E., Einarsdottir, H., Haraldsson, H., Bjarnason, G., \& Derevensky, J. (2011). Internet gambling and problem gambling among 13-18 year old adolescents in Iceland. International Journal of Mental Health and Addiction, 9, 257-263.

Philander, K., \& Fiedler, I. (2012). Online Poker in North America: Empirical evidence on its complementary effect on the offline gambling market. Retrieved from http://ssrn.com/abstract=2021993.

Pricewaterhouse Coopers. (2011). Global gaming outlook. Retrieved from http://www.pwc.com/en_GX/gx/ entertainment-media/publications/global-gaming-outlook.jhtml.

Productivity Commission. (1999). Australia's gambling industries: Final report. Canberra: Commonwealth of Australia.

Productivity Commission. (2010). Gambling (Report No. 50). Canberra: Author.

Radburn, B., \& Horsley, R. (2011). Gamblers, grinders and mavericks: The use of membership categorisation to manage identity by professional poker players. Journal of Gambling Issues, 26, 30-50.

Roy Morgan Research. (2012). Poker machine spend down to $\$ 10.2$ billion as participation continues to decline. Roy Morgan Single Source, 2012. Retrieved from http://www.roymorgan.com/news/pressreleases/2012/1881/.

Svensson, J., \& Romild, R. (2011). Incident Internet gambling in Sweden: Results from the Swedish longitudinal gambling study. International Gambling Studies, 11, 257-375.

Wardle, H., Moody, A., Griffiths, M., Orford, J., \& Volberg, R. (2011). Defining the online gambler and patterns of behaviour integration: Evidence from the British Gambling Prevalence Survey 2010. International Gambling Studies, 11, 339-356.

Williams, R. J., \& Volberg, R. A. (2009). Impact of survey description, administration format, and exclusionary criteria on population prevalence rates of problem gambling. International Gambling Studies, 9, 101-117.

Williams, R. J., \& Volberg, R. A. (2012). Population assessment of problem gambling: Utility and best practices. Report prepared for the Ontario Problem Gambling Research Centre and the Ontario Ministry of Health and Long Term Care. April 30, 2012.

Wood, R., \& Williams, R. (2010). Internet gambling: Prevalence, patterns, problems, and policy options. Final report prepared for the Ontario Problem Gambling Research Centre, Guelph, ON, Canada.

Wood, R., \& Williams, R. (2011). A comparative profile of the internet gambler: Demographic characteristics, game play patterns, and problem gambling status. New Media \& Society, 13, 1123-1141. 